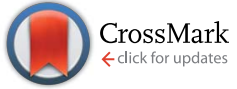

Cite this: RSC Adv., 2015, 5, 65618

Received 20th May 2015

Accepted 28th July 2015

DOI: $10.1039 / c 5 r a 09495 j$

www.rsc.org/advances

\section{Coating of bioactive glass particles with mussel- inspired polydopamine as a strategy to improve the thermal stability of poly(L-lactide)/bioactive glass composites $\uparrow$}

\author{
Aitor Larrañaga, † $^{*}$ Daniel Ramos, $\$$ Hegoi Amestoy, Ester Zuza \\ and Jose-Ramon Sarasua
}

\begin{abstract}
Fabrication of bioactive glass (BG) filled polyester composites by traditional thermoplastic processing techniques is limited because a thermal degradation reaction occurs between the $\mathrm{Si}-\mathrm{O}^{-}$groups present on the surface of the $B G$ and the $C=O$ groups present in the backbone of the polymer at high temperatures. To overcome this problem, this study looked at the effect of mussel-inspired polydopamine (PDA) coated on the surface of BG particles. Thermogravimetric analysis demonstrated the improved thermal stability of poly(L-lactide) (PLLA) composites filled with PDA-coated BG particles compared to PLLA composites filled with uncoated BG particles. Moreover, these composites were successfully manufactured by hot-pressing, showing enhanced mechanical properties in comparison to non-coated BG filled PLLA composites. Dynamic mechanical analysis indicated a good interfacial interaction between PDA-coated BG particles and the PLLA matrix, suggesting that an immobilized layer of polymer chains was formed around the BG particles. Finally, the bioactivity of PLLA samples filled with 15 vol\% of PDA-coated BG particles was confirmed via the deposition of an apatite layer on the surface of the material. In view of the results obtained it can be concluded that coating BG particles with PDA is a promising strategy as it can create composite materials with improved thermal stability and bioactivity.
\end{abstract}

\section{Introduction}

Combination of bioactive glass (BG) particles or fibers with resorbable synthetic polymers has emerged as a promising strategy for the preparation of materials whose applications range from structural implants to tissue engineering scaffolds, and in particular for bone related biomedical applications. ${ }^{1}$ On the one hand, synthesis conditions can be finely controlled to prepare resorbable synthetic polymers (e.g., poly(L-lactide) (PLLA), poly( $\varepsilon$-caprolactone) (PCL) and its copolymers (PLCL)) that have tunable mechanical properties ${ }^{2}$ and degradation rates., ${ }^{3,4}$ On the other hand, incorporation of BG imparts osteoproductivity and osteoconductivity to the bioinert polymer. ${ }^{5}$ Accordingly, the ionic dissolution products from BG (particularly silica and calcium ions) activate several families of genes that control the osteoblast cycle, mitosis and differentiation, giving rise to rapid bone regeneration. ${ }^{6,7}$ Moreover, in

University of the Basque Country (UPV/EHU), Department of Mining-Metallurgy Engineering and Materials Science \& POLYMAT, School of Engineering, Alameda de Urquijo s/n, 480130 Bilbao, Spain. E-mail: aitor.larranagae@ehu.eus; Fax: +34 94 601 3930; Tel: +34946017138

$\dagger$ Electronic supplementary information (ESI) available. See DOI: 10.1039/c5ra09495j

\$ These authors contributed to the work equally. contact with body fluids, a hydroxycarbonate apatite layer is developed on the surface of BG, this forms a strong bond with the native bone and avoids any relative motion (micromotion) of the implanted scaffold. Outside of bone related biomedical applications, recent studies have also highlighted the advantages of BG in soft tissue regeneration and wound healing. ${ }^{8,9}$

Since the aforementioned synthetic (co)polymers are thermoplastic, they are typically manufactured by injection molding, blow molding, thermoforming or extrusion. ${ }^{10}$ However, previous studies have revealed that a degradation reaction between the $\mathrm{Si}-\mathrm{O}^{-}$groups present on the surface of $\mathrm{BG}$ and the $\mathrm{C}=\mathrm{O}$ groups present in the polymer backbone occurs at high temperatures ${ }^{11-13}$ the result is a dramatic reduction in the molecular weight of the polymer matrix. This is why several studies have reported detrimental effects on the mechanical properties of the resulting composites after the incorporation of BG, when processed by traditional thermoplastic techniques. ${ }^{12-15}$

In a previous work of our group ${ }^{\mathbf{1 6}}$ a surface modification of BG particles by plasma polymerization of acrylic acid was proposed as a strategy for the improvement of the thermal stability of BG filled composite systems. Even if obtained results were promising, the homogeneity of the treatment was not optimal since it did not assure the modification of the whole surface of all particles. In the present work, coating BG particles 
with mussel-inspired polydopamine (PDA) as a strategy to maintain the thermal stability of PLLA/BG composites is proposed. PDA is a dopamine derived synthetic eumelanin polymer that contains both cathecol and amine functionalities in its backbone. ${ }^{17}$ In the case of previously proposed plasma polymerization strategy, plasma reactors with fluidized beds or circulating streams are needed to achieve and homogeneous coating. In contrast, in the strategy proposed in the present work, a thin and homogeneous PDA film can be deposited on the surface of the material spontaneously via simple immersion of substrates in a dilute aqueous solution of dopamine. ${ }^{18}$ Thus, many different substrates have been coated with PDA in recent years. ${ }^{19-24}$ However, to the best of the author's knowledge, PDA has not so far been employed on BG. In this study BG particles were first coated with PDA (mBG) and fully characterized by Fourier transform infrared spectroscopy (FTIR) and X-ray photoelectron spectroscopy (XPS). The thermal degradation behavior of PLLA/mBG was then studied by means of thermogravimetric analysis (TGA). After that, hot-pressed sheets were manufactured and their mechanical properties were analyzed via tensile test and dynamic mechanical analysis (DMA). Finally, these samples were submerged in simulated body fluid (SBF) and the formation of a hydroxyapatite layer was monitored by scanning electron microscopy (SEM) and X-ray diffractometry (XRD).

\section{Materials and methods}

\subsection{Materials}

PLLA with a weight-average molecular weight $\left(M_{\mathrm{w}}\right)$ of 160000 $\mathrm{g} \mathrm{mol}^{-1}$ and polydispersity index of 1.7 was supplied by Biomer (Germany). 45S5 Bioglass ${ }^{\circledR}$ particles were kindly supplied by Novabone ${ }^{\circledR}$ (US), their composition being (in wt\%) $45.0 \% \mathrm{SiO}_{2}$, 24.4\% $\mathrm{Na}_{2} \mathrm{O}, 24.5 \% \mathrm{CaO}$ and $6.0 \% \mathrm{P}_{2} \mathrm{O}_{5}$. To measure their size distribution, a dispersion of these particles in ethanol was prepared, and after sonication for $15 \mathrm{~min}$ a few drops were placed on a glass slide. Finally, the sample was examined under a microscope and the size distribution was determined using Image J software. The particle size was $<60 \mu \mathrm{m}$, with a mean particle size of $9 \mu \mathrm{m}$ and density of $2.75 \mathrm{~g} \mathrm{~cm}^{-3}$. Dopamine hydrochloride, tris(hydroxymethyl)aminomethane (Trizma® base), $\mathrm{NaCl}, \mathrm{NaHCO}_{3}, \mathrm{KCl}, \mathrm{K}_{2} \mathrm{HPO}_{4} \cdot 3 \mathrm{H}_{2} \mathrm{O}, \mathrm{MgCl}_{2} \cdot 6 \mathrm{H}_{2} \mathrm{O}, \mathrm{CaCl}_{2}$, $\mathrm{Na}_{2} \mathrm{SO}_{4}$ and hydrochloric acid ( $\left.\mathrm{HCl}, 37 \%\right)$ were purchased from Sigma-Aldrich (Spain). Chloroform was purchased from Panreac (Spain).

\subsection{Coating of BG particles with PDA}

In a typical experiment, $2 \mathrm{~g}$ of dopamine were dissolved in $500 \mathrm{~mL}$ of Tris- $\mathrm{HCl}$ solution $(10 \mathrm{mM}, \mathrm{pH}=8.5)$. The solution gradually turned gray due to the oxidation of the dopamine. Subsequently, $4 \mathrm{~g}$ of BG particles were added and the dispersion was stirred for $24 \mathrm{~h}$ at room temperature. Then, the surface coated BG particles, named as mBG, were collected by filtration and rinsed with distilled water until the washing liquid became colorless. Finally, the mBG particles were dried at $50{ }^{\circ} \mathrm{C}$ under reduced pressure during $48 \mathrm{~h}$. It is worth noting that $\mathrm{mBG}$ particles showed better stability in distilled water than BG particles (Fig. S1 $\dagger$ ). The hydrophilic $-\mathrm{OH}$ and $-\mathrm{NH}_{2}$ groups present in PDA may facilitate the dispersion of $\mathrm{mBG}$ particles in aqueous solutions.

\subsection{Preparation of PLLA/mBG films and sheets}

PLLA films containing 5, 10 and 15 vol\% of BG or mBG particles were prepared by solvent casting. Predetermined amounts of BG or $\mathrm{mBG}$ particles were added to a PLLA solution in chloroform ( $4 \mathrm{w} / \mathrm{v} \%$ ) and vigorously stirred for $1 \mathrm{~h}$. Finally, after chloroform evaporation the resulting films were dried at $50{ }^{\circ} \mathrm{C}$ under reduced pressure for $48 \mathrm{~h}$ in a vacuum oven.

These films were cut into small pieces and processed by hotpressing in a Collin's P200E hydraulic press as follows: once the hydraulic press reached $200{ }^{\circ} \mathrm{C}$, the polymer was put within the press between two metal plates (mold) and kept at this temperature for 5 minutes. Then, 200 bar were applied and, after 1 minute, the metal plates were cooled down with a water refrigeration system. In this way PLLA sheets of $\sim 1 \mathrm{~mm}$ thickness containing 5,10 or $15 \mathrm{vol} \%$ of $\mathrm{BG}$ or $\mathrm{mBG}$ particles were obtained.

\subsection{Characterization}

2.4.1. Characterization of $\mathbf{m B G}$ particles. The coating of BG particles with PDA was confirmed by means of FTIR, XPS and TGA. The infrared spectra of the BG and $\mathrm{mBG}$ particles were recorded on a Nicolet AVATAR 370 Fourier transform infrared spectrophotometer (FTIR). The samples were prepared as follows: a small quantity of BG or $\mathrm{mBG}$ particles was mixed with $\mathrm{KBr}$ and the mixture was manually milled until a fine powder was obtained. Finally, the resulting powder was pressed into a disc. Spectra of these samples were taken with a resolution of $2 \mathrm{~cm}^{-1}$ and averaged over 64 scans. XPS of BG and mBG particles were performed with a SPECS (Germany) instrument equipped with Phoibos 150 1D-DLD analyzer and monochromatized Al Ka $(1486.6 \mathrm{eV})$ radiation source. Survey scans (1100 to $0 \mathrm{eV}$ binding energy, BE; step energy $1 \mathrm{eV}$; dwell time $0.1 \mathrm{~s}$; pass energy $40 \mathrm{eV}$ ) were acquired with an electron take-off angle of $90^{\circ}$. The hydrocarbon peak component in the $\mathrm{C} 1 \mathrm{~s}$ spectra was set at $285.0 \mathrm{eV}$ to correct sample charging. The spectrometer was previously calibrated with the peak of Ag 3d 5/2 (368.28 eV). For TGA, 10-15 mg of $\mathrm{BG}$ or $\mathrm{mBG}$ particles were placed in platinum pans and heated from room temperature to $700{ }^{\circ} \mathrm{C}$ within a thermogravimetric analyzer (TGA Q50-0545), at a heating rate $(\beta)$ of $5{ }^{\circ} \mathrm{C} \mathrm{min}^{-1}$ and a

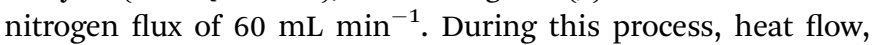
sample temperature, sample weight and its time derivative were recorded continuously. Thus, the mass of the PDA deposited on the surface of $\mathrm{mBG}$ particles was determined.

2.4.2. Thermal stability of solvent casting films. The thermal stability of solvent casting films was analyzed by dynamic and isothermal TGA experiments. Samples of 10-15 $\mathrm{mg}$ were heated from room temperature to $500{ }^{\circ} \mathrm{C}$ at a rate of $\beta=5{ }^{\circ} \mathrm{C} \min ^{-1}$, with the heat flow, sample temperature, sample weight and its time derivative being recorded continuously. Within this temperature range, the polymer is completely degraded but the bioactive particles did not suffer any 
significant weight losses. For isothermal experiments, samples of 10-15 mg were heated at $10{ }^{\circ} \mathrm{C} \mathrm{min}^{-1}$ up to the desired temperature $\left(210^{\circ} \mathrm{C}\right)$ and maintained at this same temperature for $20 \mathrm{~min}$.

2.4.3. Mechanical characterization of hot-pressed sheets. Tensile tests of hot-pressed sheets were performed with an Instron 5565 testing machine at a crosshead displacement rate of $5 \mathrm{~mm} \mathrm{~min}{ }^{-1}$. This test was performed at $21 \pm 2{ }^{\circ} \mathrm{C}$ and $50 \pm$ $5 \%$ relative humidity following ISO 527-2. Dynamic mechanical measurements of these sheets were carried out using a DMA/SDTA861e (Mettler Toledo) in tensile mode. Samples were heated from 20 to $100{ }^{\circ} \mathrm{C}$ at a heating rate of $3{ }^{\circ} \mathrm{C} \mathrm{min}^{-1}$, a frequency of $1 \mathrm{~Hz}$ with the displacement and force amplitude being maintained at $25 \mu \mathrm{m}$ and $0.5 \mathrm{~N}$, respectively. The molecular weights of the samples before and after hot-pressing were analyzed by gel permeation chromatography (GPC) using a Waters 1515 GPC apparatus equipped with two Styragel columns $\left(10^{2}\right.$ to $\left.10^{4} \AA\right)$. All the samples were prepared at a concentration of $10 \mathrm{mg} \mathrm{mL} \mathrm{m}^{-1}$ in chloroform and were filtered prior to analysis using syringe filters (Acrodisc $₫$, $0.45 \mu \mathrm{m}$, Waters). Chloroform was used as an eluent, with a flow rate of $1 \mathrm{~mL} \mathrm{~min}^{-1}$ and polystyrene standards (Shodex Standards, SM-105) were used to obtain a primary calibration curve.

2.4.4. Bioactivity study. For the bioactivity study, PLLA sheets filled with 15 vol\% of mBG particles were submerged in a simulated body fluid (SBF) at $37{ }^{\circ} \mathrm{C}$ and at a surface area to volume ratio equal to $0.1 \mathrm{~cm}^{-1}$. SBF, with solution ion concentrations similar to those of blood plasma, was prepared by dissolving reagent-grade chemicals of $\mathrm{NaCl}, \mathrm{NaHCO}_{3}, \mathrm{KCl}$, $\mathrm{K}_{2} \mathrm{HPO}_{4} \cdot 3 \mathrm{H}_{2} \mathrm{O}, \mathrm{MgCl}_{2} \cdot 6 \mathrm{H}_{2} \mathrm{O}, \mathrm{CaCl}_{2}, \mathrm{Na}_{2} \mathrm{SO}_{4}$ and buffered at a $\mathrm{pH}$ value of 7.4 at $37{ }^{\circ} \mathrm{C}$ with Trizma ${ }^{\circledR}$ base and $\mathrm{HCl}^{25}$ Complementary studies ${ }^{\mathbf{2 6}}$ indicate that the SBF must be changed regularly because the concentration of cations decreases during the experiments due to chemical changes in the samples. In this study, SBF was changed every 3 days. Samples were taken out of the SBF after being submerged for 28 days in SBF, these were rinsed in abundant deionized water before drying at room temperature for $24 \mathrm{~h}$ and then for another $24 \mathrm{~h}$ in vacuum.

The Ca-P layer developed on the surface of samples was characterized using scanning electron microscopy (SEM) (HITACHI S-3400). Samples were coated with a $150 \AA$ Alayer of gold in a JEL Ion Sputter JFC-1100 at $1200 \mathrm{~V}$ and $5 \mathrm{~mA}$.

The formation and crystallization of hydroxyapatite was confirmed by means of X-ray difractometry (XRD). The X-ray powder diffraction patterns were collected by a PHILIPS X'PERT PRO automatic diffractometer operating at $40 \mathrm{kV}$ and $40 \mathrm{~mA}$, in theta-theta configuration, secondary monochromator with $\mathrm{Cu}-\mathrm{K} \alpha$ radiation $(\lambda=1.5418 \AA)$ and a PIXcel solid state detector. Data were collected from 10 to $50^{\circ} 2 \theta$ (step size $=0.026$ and time per step $=0.8 \mathrm{~s}$ per channel) at room temperature. A fixed divergence and anti-scattering slit to produce a constant volume of sample illumination were used.

Additionally, mBG particles were directly submerged in SBF at $37{ }^{\circ} \mathrm{C}$. After 1, 3 and 7 days, they were collected, rinsed with distilled water and dried under reduced pressure prior to FTIR analysis.

\section{Results and discussion}

\subsection{Coating of BG particles with PDA}

The color of BG particles turned from white to gray after the coating process, indicating the formation of a layer of PDA on the surface of BG particles (Fig. 1).

The successful coating of PDA on the surface of BG particles was further confirmed by XPS (Fig. 2 and Table 1) and FTIR (Fig. S2 $\dagger$ ). The XPS survey spectra of BG particles (Fig. 2b) indicate the presence of $\mathrm{O} 1 \mathrm{~s}(531.6 \mathrm{eV}), \mathrm{C} 1 \mathrm{~s}(285.0 \mathrm{eV}), \mathrm{Ca} 2 \mathrm{p}$ (346.6 eV), Na 1s (1071.6 eV) and Si 2p (102.6 eV) on the surface of the particles. After PDA coating, the XPS survey spectra of mBG particles showed an additional peak at $399.6 \mathrm{eV}$, which corresponds to $\mathrm{N} 1 \mathrm{~s}$. The presence of nitrogen is ascribed to the amine functionalities in the PDA backbone and confirms the coating of PDA on the surface of mBG particles. The N/C signal ratio was 0.089 , that is very close to the value reported for polydopamine $(\mathrm{N} / \mathrm{C}=0.086) .{ }^{24}$ In FTIR (Fig. S2 $\dagger$ ) the main characteristics of the spectrum of BG particles are attributed to the amorphous silica glass. The two bands at 1050 and $950 \mathrm{~cm}^{-1}$ are assigned to $\mathrm{Si}-\mathrm{O}-\mathrm{Si}$ stretching vibration and the band at $450 \mathrm{~cm}^{-1}$ is assigned to $\mathrm{Si}-\mathrm{O}-\mathrm{Si}$ bending vibration. ${ }^{27}$ In contrast, the main bands of mBG spectra appeared at 1595 and $1505 \mathrm{~cm}^{-1}$, this can be assigned to $\nu_{\text {ring }}(\mathrm{C}=\mathrm{C})$ and $\nu_{\text {ring }}(\mathrm{C}=\mathrm{N})$ stretching modes, respectively, indicating that aromatic amines were present in the coated PDA film. Moreover, a broad band was observed between $3700-2500 \mathrm{~cm}^{-1}$, this can be assigned to the $\nu(\mathrm{N}-\mathrm{H})$ and $\nu(\mathrm{O}-\mathrm{H})$ stretching modes. ${ }^{28}$

Finally, the thermal stability of BG and $\mathrm{mBG}$ particles up to $700{ }^{\circ} \mathrm{C}$ was analyzed by TGA (Fig. S3†). In this temperature range, BG particles did not suffer any significant weight losses. In contrast, $\mathrm{mBG}$ lost $13 \%$ of its initial weight at the end of the process. This weight loss can only be attributed to the presence of a PDA coating on the surface of $\mathrm{mBG}$ particles.

\subsection{Thermal stability of PLLA/BG and PLLA/mBG composites}

Fig. 3 shows the thermogravimetry (TG) and differential thermogravimetry (DTG) profiles of PLLA composites prepared by solvent casting. From this figure, peak $\left(T_{\text {peak }}\right)$ and onset $\left(T_{\text {onset }}\right.$, calculated from the inflection point of the thermogravimetry profile) degradation temperatures can be determined, these are summarized in Table 2 . A first weight loss ( $\sim 10 \%$ weight loss) was observed in all cases at around $100{ }^{\circ} \mathrm{C}$ that can be associated to some water present in the samples. For pristine PLLA, $T_{\text {onset }}$ and $T_{\text {peak }}$ were $303.5 \pm 11.5$ and $338.5 \pm 8.5{ }^{\circ} \mathrm{C}$, respectively.
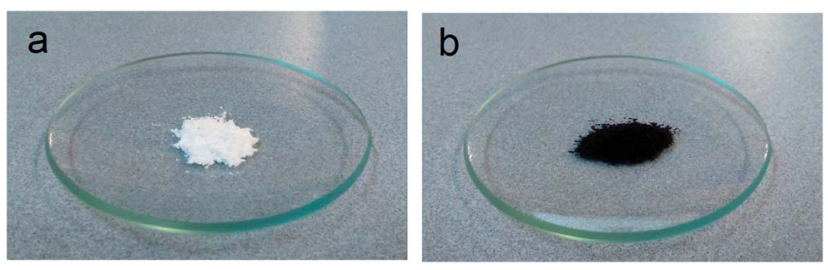

Fig. 1 Picture of BG particles before (a) and after (b) PDA coating. 


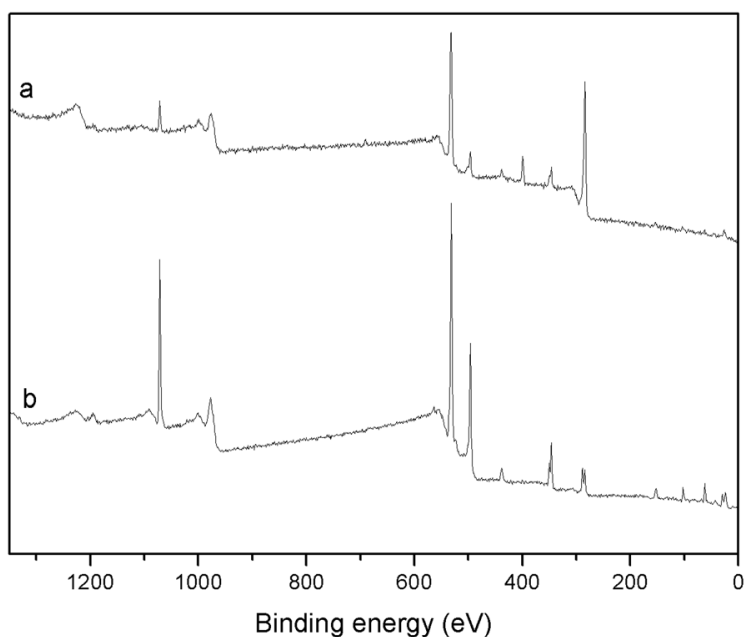

Fig. 2 XPS survey spectra of $\mathrm{mBG}$ (a) and BG (b) particles.

Table 1 Surface composition of BG and mBG particles from XPS

\begin{tabular}{lll}
\hline & Atomic\% & \\
\cline { 2 - 3 } Element & BG particles & mBG particles \\
\hline O 1s & 48.2 & 22.6 \\
C 1s & 24.4 & 64.8 \\
N 1s & - & 5.8 \\
Ca 2p & 6.1 & 2.2 \\
Na 1s & 12.8 & 1.7 \\
Si 2p & 8.4 & 2.9
\end{tabular}

These values decreased constantly as the content of BG particles increased. For example, the $T_{\text {onset }}$ and $T_{\text {peak }}$ values for the sample containing $5 \mathrm{vol} \%$ of BG particles were $202.5 \pm 11.5$ and $277.5 \pm$ $2.5^{\circ} \mathrm{C}$ respectively. In the case of the sample filled with $15 \mathrm{vol} \%$ of BG particles these temperatures were $190.0 \pm 1.0$ and $248.0 \pm$ $1.5{ }^{\circ} \mathrm{C}$ respectively. Moreover, the peak from the DTG profile became broader as the content of BG particles increased, suggesting a more complex degradation mechanism in those samples filled with BG particles. As previously reported, ${ }^{11-13}$ a degradation reaction between the $\mathrm{Si}^{-} \mathrm{O}^{-}$groups present on the surface of the particles and the $\mathrm{C}=\mathrm{O}$ groups in the polymer backbone occurs at high temperatures. This degradation reaction results in the random scission of PLLA polymer chains; hence, both $T_{\text {onset }}$ and $T_{\text {peak }}$ dramatically decrease in the presence of BG particles. In contrast, coating PDA on the surface of mBG particles improved the thermal stability of PLLA composites. In this sense, PLLA samples containing $15 \mathrm{vol} \%$ of $\mathrm{mBG}$ particles had $T_{\text {onset }}$ and $T_{\text {peak }}$ values of $282.5 \pm 1.1$ and $309.0 \pm 1.0{ }^{\circ} \mathrm{C}$, respectively, which are much closer to the values calculated for pristine PLLA. In addition, the peak in the DTG profile did not obviously become broader as the content of $\mathrm{mBG}$ particles in the composite increased, suggesting that the degradation reaction between the $\mathrm{Si}-\mathrm{O}^{-}$groups present on the surface of the particles and the $\mathrm{C}=\mathrm{O}$ groups in the polymer backbone was impeded.

Results from isothermal treatments (Fig. S4 $\uparrow$ and Table 2) also demonstrated the improved thermal stability of samples containing PDA-coated mBG particles with respect to their noncoated BG filled counterparts. For example, PLLA samples containing $15 \mathrm{vol} \%$ of BG particles (PLLA 15BG), lost almost $50 \%$ of their initial mass after being subjected to the isothermal treatment at $210{ }^{\circ} \mathrm{C}$ for $20 \mathrm{~min}$, showing a degradation rate of $2.1 \pm 0.1 \%$ per min. In contrast, the samples containing $15 \mathrm{vol} \%$ of mBG particles (PLLA $15 \mathrm{mBG}$ ), only lost $6.7 \%$ of their initial mass after the same isothermal treatment and presented a degradation rate of $0.03 \pm 0.003 \%$ per min.

In view of the results obtained from TGA analysis, it can be clearly concluded that the surface modification of BG particles with PDA is a promising strategy to improve the thermal stability of BG filled PLLA composites. The PDA layer on the surface of BG particles may impede the degradation reaction between the $\mathrm{Si}^{-} \mathrm{O}^{-}$groups present on the surface of the particles and the $\mathrm{C}=\mathrm{O}$ groups in the polymer backbone. As a result, those samples containing mBG particles showed $T_{\text {onset }}$ and $T_{\text {peak }}$ values much closer to those of pristine PLLA and at the same time are able to maintain their initial mass during an isothermal treatment at $210{ }^{\circ} \mathrm{C}$.

\subsection{Mechanical properties of PLLA/BG and PLLA/mBG composites}

For the mechanical characterization of the composites, PLLA sheets containing 5,10 or $15 \mathrm{vol} \%$ of BG or mBG particles were manufactured by hot-pressing and subsequently, dumbbellshaped samples were punched out from these sheets. After hot-pressing, samples containing BG particles had a yellowish color (Fig. S5 $\dagger$ ) and were brittle, indicating a possible degradation process of the samples during the thermoplastic processing. Thus, their molecular weight was analyzed before $\left(M_{\mathrm{n} 0}\right)$ and after the hot-pressing $\left(M_{\mathrm{n}}\right)$. As can be seen in Table 3, pristine PLLA did not suffer any significant loss of molecular weight during the processing. In contrast, those samples containing 5, 10 and $15 \mathrm{vol} \%$ of BG particles lost, respectively, 25, 63 and $83 \%$ of their initial molecular weight. As demonstrated in the previous section, modification of particles with PDA brought about an improved thermal stability in the composites. Accordingly, those samples containing 5, 10 and $15 \mathrm{vol} \%$ of mBG particles only lost 7,9 and $14 \%$ of their initial molecular weight.

The sharp decrease in the molecular weight of those samples containing BG particles had a detrimental effect on the final mechanical properties of the composites (Fig. S6 $\dagger+$ Table 3). Pristine PLLA is a stiff and rigid polymer showing high Young's modulus (1558.2 $\pm 109.9 \mathrm{MPa})$, high tensile strength $(47.7 \pm 5.0$ $\mathrm{MPa})$ but low elongation at break $(3.9 \pm 0.5 \mathrm{MPa})$. When 5 or $10 \mathrm{vol} \%$ of BG particles were incorporated, the Young's modulus increased slightly, due to the presence of stiff inorganic fillers within the soft polymer matrix. However, the samples became too brittle and as a result the ultimate tensile strength was clearly reduced with respect to pristine PLLA. For example, PLLA filled with 10 vol\% of BG particles (PLLA 10BG) showed an elongation at break and ultimate tensile strength of $0.5 \pm 0.2 \%$ and $8.6 \pm 2.8 \mathrm{MPa}$, respectively. PLLA filled with $15 \mathrm{vol} \%$ of BG particles was so brittle that the tensile test could not be carried 

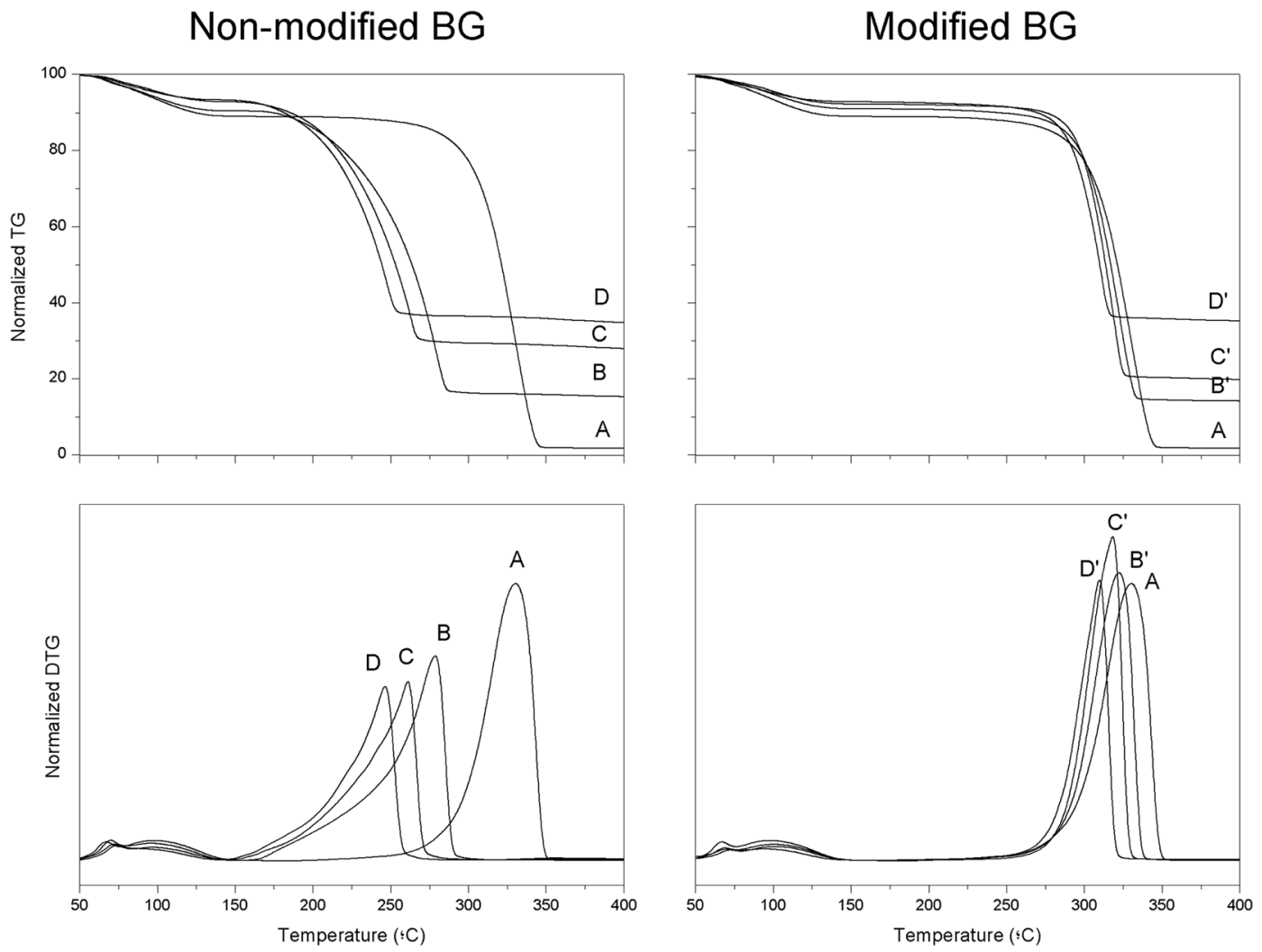

Fig. 3 TG and DTG profiles of PLLA composites containing 5, 10 or 15 vol\% of BG or mBG particles.

out. Even if some deterioration in the mechanical properties was also observed for PLLA composites containing mBG particles, these samples were able to maintain their mechanical properties much better than when non-coated BG particles were incorporated. In general, the Young's modulus of the samples steadily increased with the concentration of mBG particles, reaching $1703.7 \pm 119.3 \mathrm{MPa}$ for the samples containing $15 \mathrm{vol} \%$ of mBG particles (PLLA 15mBG). The incorporation of $\mathrm{mBG}$ particles also resulted in the embrittlement of the samples, so lower values of elongation at break and tensile strength were recorded as the concentration of $\mathrm{mBG}$ particles within the PLLA matrix increased. For example, elongation at break and tensile strength were reduced from the initial values of $3.9 \pm 0.5 \%$ and $47.7 \pm 5 \mathrm{MPa}$ for pristine PLLA to $1.9 \pm 0.2 \%$
Table 3 Young's modulus $(E)$, ultimate tensile strength $\left(\sigma_{\mathrm{u}}\right)$, elongation at break $\left(\varepsilon_{\mathrm{u}}\right)$ and number-averaged molecular weight ratio $\left(M_{n} / M_{n 0}\right)$ of hot-pressed PLLA samples containing 5, 10 or 15 vol\% of BG or mBG particles

\begin{tabular}{llrll}
\hline Sample & $E(\mathrm{MPa})$ & $\sigma_{\mathrm{u}}(\mathrm{MPa})$ & $\varepsilon_{\mathrm{u}}(\%)$ & $M_{\mathrm{n}} / M_{\mathrm{n} 0}$ \\
\hline PLLA & $1558.2 \pm 109.9$ & $47.7 \pm 5.0$ & $3.9 \pm 0.5$ & $0.99 \pm 0.05$ \\
PLLA 5BG & $1569.7 \pm 81.6$ & $28.7 \pm 3.3$ & $2.0 \pm 0.3$ & $0.75 \pm 0.01$ \\
PLLA 5mBG & $1560.7 \pm 84.5$ & $41.3 \pm 1.3$ & $2.9 \pm 0.3$ & $0.93 \pm 0.03$ \\
PLLA 10BG & $1687.8 \pm 229.7$ & $8.6 \pm 2.8$ & $0.5 \pm 0.2$ & $0.37 \pm 0.01$ \\
PLLA 10mBG & $1687.6 \pm 109.0$ & $39.4 \pm 3.3$ & $2.5 \pm 0.2$ & $0.91 \pm 0.01$ \\
PLLA 15BG & - & - & - & $0.17 \pm 0.03$ \\
PLLA 15mBG & $1703.7 \pm 119.3$ & $37.9 \pm 4.1$ & $1.9 \pm 0.2$ & $0.86 \pm 0.03$
\end{tabular}

Table $2 T_{\text {peak, }} T_{\text {onset, }}$ degradation rate and final weight of the samples subjected to dynamic and isothermal treatment within the TGA

\begin{tabular}{lllccc}
\hline Sample & Vol\% BG & $T_{\text {peak }}\left({ }^{\circ} \mathrm{C}\right)$ & $T_{\text {onset }}\left({ }^{\circ} \mathrm{C}\right)$ & Deg. rate $^{a}(\%$ per min) & Final weight $(\%)$ \\
\hline PLLA & 0 & $338.5 \pm 8.5$ & $303.5 \pm 11.5$ & $0.03 \pm 0.02$ & $89.9 \pm 0.8$ \\
PLLA 5BG & $7.2 \pm 1.5$ & $277.5 \pm 2.5$ & $202.5 \pm 1.0$ & $1.2 \pm 0.1$ & $67.3 \pm 1.8$ \\
PLLA 5mBG & $6.3 \pm 0.9$ & $322.5 \pm 1.0$ & $293.5 \pm 1.0$ & $0.09 \pm 0.03$ & $89.8 \pm 0.1$ \\
PLLA 10BG & $16.9 \pm 2.0$ & $258.5 \pm 3.5$ & $194.5 \pm 1.5$ & $1.9 \pm 0.1$ & $51.1 \pm 0.8$ \\
PLLA 10mBG & $10.2 \pm 1.4$ & $318.5 \pm 0.5$ & $291.5 \pm 1.0$ & $0.04 \pm 0.001$ & $92.1 \pm 0.1$ \\
PLLA 15BG & $20.4 \pm 1.1$ & $248.0 \pm 1.5$ & $190.0 \pm 1.0$ & $2.1 \pm 0.1$ & $51.3 \pm 1.9$ \\
PLLA 15mBG & $20.1 \pm 1.8$ & $309.0 \pm 1.0$ & $282.5 \pm 1.1$ & $0.03 \pm 0.003$ & $93.3 \pm 0.1$
\end{tabular}

${ }^{a}$ Calculated from the slope of weight loss in the isothermal experiments. ${ }^{b}$ Final weight of the samples after 20 min at $210{ }^{\circ} \mathrm{C}$. 
and $37.9 \pm 4.1 \mathrm{MPa}$ for PLLA $15 \mathrm{mBG}$ respectively. The embrittlement of the samples due to the incorporation of mBG particles can be explained by, on the one hand, a slightly lower molecular weight of the PLLA matrix in those samples containing $\mathrm{mBG}$ particles and on the other, the incorporation of brittle glass particles within the polymer matrix which could result in poorer mechanical properties of the resulting composite.

The dynamic mechanical properties of the samples processed by hot-pressing were also analyzed in tensile mode (Fig. 4 and Table 4). Fig. 4 shows the storage modulus $\left(E^{\prime}\right)$ and the damping ( $\tan \delta=E^{\prime \prime} / E^{\prime}$, where $E^{\prime \prime}$ is the loss modulus) of pristine PLLA and PLLA filled with BG or $\mathrm{mBG}$ particles. It can easily be seen that the transition from the glassy to the rubbery state occurred at lower temperatures as the content of non-coated BG particles increased. For example, the onset temperature at which this transition occurred dropped from $50.0{ }^{\circ} \mathrm{C}$ for pristine PLLA to 43.5 ${ }^{\circ} \mathrm{C}$ for PLLA 15BG (Table 4). As previously mentioned, those samples containing BG particles suffered a dramatic decrease in molecular weight due to the degradation reaction between the BG particles and the polymer matrix during hot-pressing. In this particular case, PLLA showed a $M_{\mathrm{w}}$ of $160 \times 10^{3} \mathrm{~g} \mathrm{~mol}^{-1}$ whereas PLLA 15BG had a $M_{\mathrm{w}}$ of $81 \times 10^{3} \mathrm{~g} \mathrm{~mol}^{-1}$. It is well known that several properties of polymers are maintained almost constant above a critical molecular weight but sharply decrease below this value. ${ }^{29}$ The lower molecular weight of these samples meant shorter polymer chains with higher mobility and consequently the transition from glassy to rubbery state takes place at lower temperatures. The opposite situation was observed when mBG particles were incorporated. In this case, the transition from glassy to rubbery moved toward higher temperatures as the content of mBG particles increased, indicating a good interaction between the polymer matrix and the filler. ${ }^{30}$

Above the transition from glassy to rubbery state, the storage modulus $\left(E^{\prime}\right)$ of PLLA, PLLA 5BG and PLLA 10BG decreased sharply and had values between 3.1 and $3.7 \mathrm{MPa}$ in all cases. An increase in storage modulus was observed around $80{ }^{\circ} \mathrm{C}$, this could be related to the cold crystallization of PLLA chains. ${ }^{31}$ This increase in $E^{\prime}$ was more evident and occurred at lower temperatures with the PLLA 15BG sample. As previously mentioned, a sharp decrease in molecular weight was observed during hot-pressing for this sample, resulting in the formation of shorter polymer chains with higher mobility. These chains are able to reorganize themselves toward a more ordered macromolecular state at lower temperatures than samples with a higher molecular weight. In those samples containing mBG particles, the storage modulus above the glass transition $\left(E^{\prime}{ }_{75}{ }^{\circ} \mathrm{C}\right)$ was enhanced as the content of mBG particles within the composite increased, indicating a good interfacial interaction between the polymer matrix and the inorganic filler. For example, pristine PLLA had a $E^{\prime}{ }_{75}{ }^{\circ} \mathrm{C}$ of $3.5 \mathrm{MPa}$, whereas PLLA $15 \mathrm{mBG}$ showed a value of $14.3 \mathrm{MPa}$.

The interaction between BG particles and the PLLA matrix can also be discussed in terms of $\tan \delta$ values. Composite dissipation is attributable not only to the amount of matrix present in the composite, but also to the filler-matrix
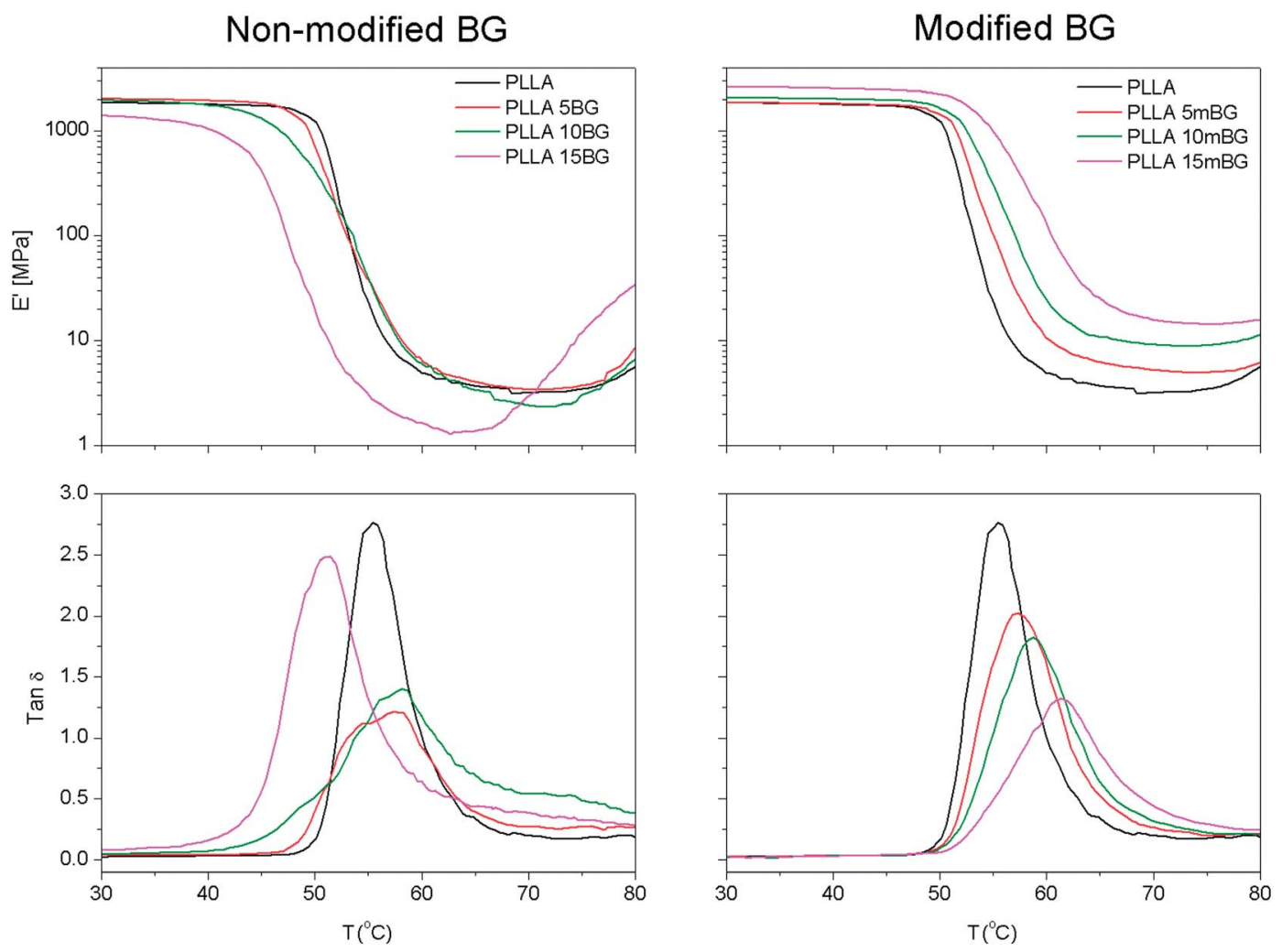

Fig. $4 E^{\prime}$ and $\tan \delta$ of PLLA composites containing 5, 10 or 15 vol\% of BG or mBG particles. 
Table 4 Dynamic mechanical properties of PLLA composites containing 5,10 or 15 vol\% of BG or mBG particles

\begin{tabular}{lcllll}
\hline Sample & $\tan \delta$ & $\begin{array}{l}T_{\text {onset }}{ }^{a} \\
\left({ }^{\circ} \mathrm{C}\right)\end{array}$ & $\begin{array}{l}E^{\prime}{ }_{35}^{\circ}{ }^{\circ} \mathrm{C} \\
(\mathrm{MPa})\end{array}$ & $\begin{array}{l}E^{\prime}{ }_{75}^{\circ} \mathrm{C} \\
(\mathrm{MPa})\end{array}$ & $\begin{array}{l}M_{\mathrm{w}}\left(\mathrm{g} \mathrm{mol}^{-1}\right) \\
\left(\times 10^{3}\right)\end{array}$ \\
\hline PLLA & 2.75 & 50.0 & 1835.6 & 3.5 & 160 \\
PLLA 5BG & 1.20 & 48.3 & 1992.9 & 3.7 & 105 \\
PLLA 5mBG & 2.19 & 50.8 & 1840.4 & 4.9 & 147 \\
PLLA 10BG & 1.40 & 47.4 & 1889.5 & 3.1 & 93 \\
PLLA 10mBG & 1.85 & 51.7 & 2047.9 & 9.0 & 149 \\
PLLA 15BG & 2.48 & 43.5 & 1303.0 & 11.8 & 81 \\
PLLA 15mBG & 1.17 & 52.9 & 2577.7 & 14.3 & 143
\end{tabular}

${ }^{a}$ Calculated as the temperature where the initial value of $E^{\prime}$ departs from linearity.

interactions at the interfaces as these will tend to form layers of immobilized interphase. ${ }^{32}$ Since BG particles by themselves do not contribute to damping at the glass transition of the polymer (i.e., transition from glassy to rubbery state), composite dissipation may be given by the following equation:

$$
(\tan \delta)_{c} /(\tan \delta)_{m}=1-b V_{\mathrm{f}}
$$

where $m$ and $c$ indices refer to matrix and composite dissipation, respectively, $V_{\mathrm{f}}$ is the filler volume content and $b$ is a parameter introduced to correct the volume fraction of reinforcement due to the formation of a layer of immobilized interphase resulting from filler-matrix interaction. When $b=1$ there is no formation of an immobilized layer and thus the composite damping is given by that of the amount of matrix present in the composite. When $b>1$ the strength of the fillermatrix interactions lead to the formation of an immobilized layer. The stronger the interfacial interactions, the thicker the immobilized layer and the higher the value of parameter $b$. Therefore, $b$ can also be interpreted in terms of adhesion at the filler-matrix interphase.

As can be observed in Fig. 5, the results obtained for PLLA samples containing $\mathrm{mBG}$ particles could be fitted $\left(R^{2}>0.99\right)$ using eqn (1). The value for $b$ was higher than $1(b=2.9)$, indicating the formation of an immobilized layer of polymer chains around mBG particles, which can be ascribed to a good filler-matrix interaction. In contrast, the values obtained for samples containing BG particles could not be fitted using eqn (1). For PLLA 5BG and PLLA 10BG samples, the $(\tan \delta)_{c} /(\tan \delta)_{m}$ values were below those that correspond to $b=1$. However, the $(\tan \delta)_{c} /$ $(\tan \delta)_{m}$ for the PLLA 15BG sample was higher than $b=1$. This fact, together with the decrease in the temperature at which the peak of $\tan \delta$ was recorded for the PLLA 15BG sample, could be associated to a plasticization effect. ${ }^{33,34}$ However, the embrittlement observed in tensile test for PLLA 15BG sample does not support this hypothesis, since a plasticization effect may have resulted in higher elongation at break for this sample. Thus, the observed higher $\tan \delta$ values can be ascribed to the presence of shorter chains with higher mobility. Moreover, these short chains may possibly be located around BG particles and therefore lower the interfacial adhesion between the filler and the polymer matrix.

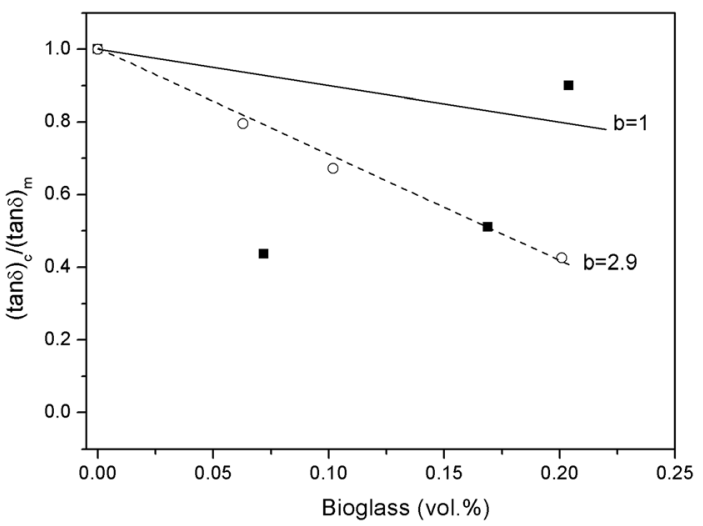

Fig. $5(\tan \delta)_{c} /(\tan \delta)_{m}$ values versus the BG content in the composite for samples filled with BG $(\mathbf{\square})$ or $\mathrm{mBG}$ particles $(O)$.

\subsection{Bioactivity study}

In the previous sections, the successful coating of BG particles with mussel-inspired PDA and the improved thermal stability of the resulting composites is highlighted. However, the main reason behind the incorporation of BG particles into synthetic polymer matrices is to impart bioactivity to the biologically inert polymer. Accordingly, in this section the bioactivity of a PLLA sample containing $15 \mathrm{vol} \%$ of mBG particles (PLLA 15mBG) was analyzed by submerging these samples in SBF. Fig. 6 shows SEM micrographs of the surface of PLLA $15 \mathrm{mBG}$ after being submerged in SBF for 28 days. Ca-P deposits were clearly observed on the surface of the sample by SEM, presenting the typical "cauliflower" morphology of hydroxyapatite.

To further demonstrate the presence of hydroxyapatite on the surface of these samples, XRD analysis was performed. As can be seen in Fig. 7, peaks corresponding to crystalline hydroxyapatite were discernible in the difractogram at $32^{\circ}$ and $26^{\circ}$ after 28 days submerged in SBF.

Moreover, mBG particles were directly immersed in SBF. At different time points $(0,1,3$ and 7 days) the FTIR spectra of these particles were recorded (Fig. S7 $\dagger$ ). The peak at $1080 \mathrm{~cm}^{-1}$ corresponds to $\nu_{3}$ vibration of $\mathrm{PO}_{4}{ }^{3-}$, whereas the peak at $1458 \mathrm{~cm}^{-1}$ corresponds to $\nu_{3}$ vibration of $\mathrm{CO}_{3}{ }^{2-}$. Each of these peaks increased over incubation time, representing the growth of a carbonated apatite mineral on the surface of $\mathrm{mBG}$ particles.

Several studies have demonstrated the enhanced deposition of hydroxyapatite layer on the surface of PDA-coated

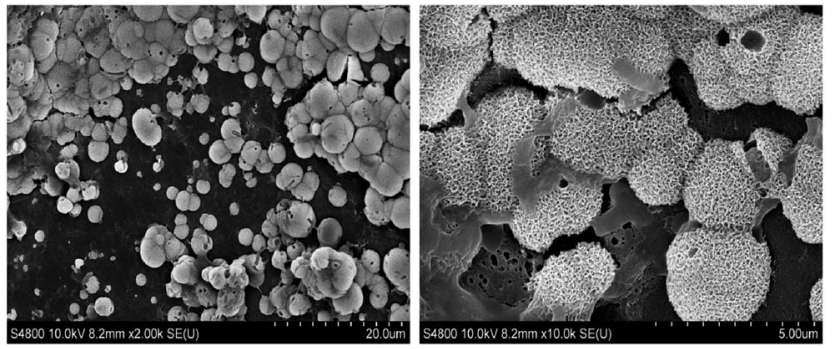

Fig. 6 SEM micrographs of PLLA 15mBG samples submerged in SBF for 28 days. 


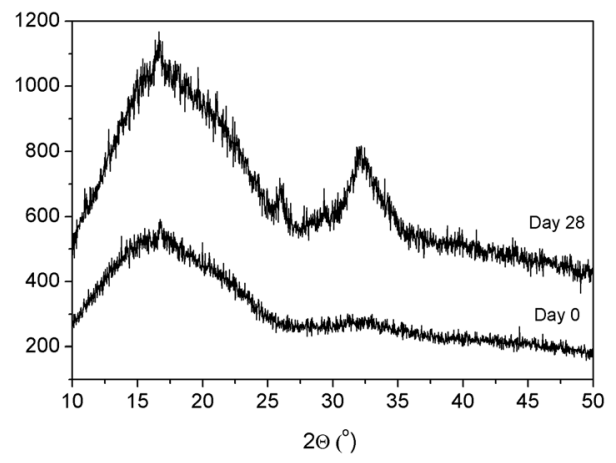

Fig. 7 XRD patterns of PLLA $15 \mathrm{mBG}$ after processing and after immersion in SBF for 28 days.

materials. ${ }^{35-39}$ The abundant catecholamine moieties provided by PDA act as a $\mathrm{Ca}^{2+}$ ion binder, facilitating the subsequent formation of hydroxyapatite crystals on the surface of the coated materials. In this study, mineralization of hydroxyapatite on the surface of PLLA samples filled with mBG particles can be ascribed to two reasons: firstly, cation $\left(\mathrm{Na}^{+}\right.$and $\left.\mathrm{Ca}^{2+}\right)$ exchange from mBG particles with $\mathrm{H}^{+}$from solution, creating silanol bonds (Si-OH) forming a silica-rich network. This network facilitates the migration of $\mathrm{Ca}^{2+}$ and $\mathrm{PO}_{4}{ }^{3-}$ from the bioactive glass bulk to the surface, leading to the formation of an amorphous calcium phosphate $\left(\mathrm{CaO}-\mathrm{P}_{2} \mathrm{O}_{5}\right)$ rich layer. Then, by incorporation of $\mathrm{OH}^{-}$and $\mathrm{CO}_{3}{ }^{2-}$ anions from solution, the amorphous $\mathrm{CaO}-\mathrm{P}_{2} \mathrm{O}_{5}$ layer is crystallized to form crystalline hydroxyapatite. Secondly, binding $\mathrm{Ca}^{2+}$ from solution with catecholamine moieties from polydopamine that can act as nucleation points for further crystalline hydroxyapatite formation.

\section{Conclusion}

In the present work, coating BG particles with mussel-inspired PDA is presented as a strategy to improve the thermal stability of PLLA composites. TGA analysis demonstrated that those samples filled with $\mathrm{mBG}$ particles showed improved thermal stability with respect to samples filled with non-coated BG particles. As a result, PLLA sheets containing mBG particles were successfully manufactured by hot-pressing, with their mechanical properties being much higher than PLLA composites filled with non-coated BG particles. DMA results indicated a good interaction between MBG particles and the PLLA matrix, as suggested by the formation of an immobilized interphase between the filler and the matrix. Finally, the bioactivity of these samples was analyzed for up to 28 days. The results obtained confirmed apatite layer formation on the surface of mBG filled PLLA samples.

\section{Acknowledgements}

The authors are grateful for funds from the Basque Government, Department of Education, Universities and Research (GIC12/161-IT-632-13) and Dept. of Industry (IE10/276). A.L. thanks the University of the Basque Country (UPV-EHU) for a postdoctoral grant. SGIker technical services (UPV/EHU, MEC, GV/EJ, European Social Fund) are gratefully acknowledged for SEM, XRD and XPS support.

\section{References}

1 K. Rezwan, Q. Z. Chen, J. Blaker and A. R. Boccaccini, Biodegradable and Bioactive Porous Polymer/Inorganic Composite Scaffolds for Bone Tissue Engineering, Biomaterials, 2006, 27, 3413-3431.

2 J. Fernández, A. Etxeberría and J. R. Sarasua, Synthesis, Structure and Properties of Poly(L-lactide-co- $\varepsilon$-caprolactone) Statistical copolymers, J. Mech. Behav. Biomed. Mater., 2012, 9, 100-112.

3 J. Fernández, A. Larrañaga, A. Etxeberría and J. R. Sarasua, Effects of Chain Microstructures and Derived Crystallization Capability on Hydrolytic Degradation of Poly(L-lactide/E-caprolactone) Copolymers, Polym. Degrad. Stab., 2013, 98, 481-489.

4 J. Fernández, A. Larrañaga, A. Etxeberría, W. Wang and J. R. Sarasua, A New Generation of Poly(lactide/ $\varepsilon^{-}$ caprolactone) Polymeric Biomaterials for Application in the Medical Field, J. Biomed. Mater. Res., Part A, 2014, 102, 3573-3584.

5 L. L. Hench, D. L. Wheeler and D. C. Greenspan, Molecular Control of Bioactivity in Sol-Gel Glasses, J. Sol-Gel Sci. Technol., 1998, 13, 245-250.

6 I. D. Xynos, A. J. Edgar, L. D. K. Buttery, L. L. Hench and J. M. Polak, Gene-Expression Profiling of Human Osteoblasts Following Treatment with the Ionic Products of Bioglass 45S5 Dissolution, J. Biomed. Mater. Res., 2001, 55, 151-157.

7 A. Larrañaga, A. Alonso-Varona, T. Palomares, E. RubioAzpeitia, P. Aldazabal, F. J. Martin and J. R. Sarasua, Effect of Bioactive Glass Particles on Osteogenic Differentiation of Adipose-Derived Mesenchymal Stem Cells Seeded on Lactide and Caprolactone Based Scaffolds, J. Biomed. Mater. Res., Part A, 2015, DOI: 10.1002/jbm.a.35525.

8 V. Miguez-Pacheco, L. L. Hench and A. R. Boccaccini, Bioactive Glasses Beyond Bone and Teeth: Emerging Applications in Contact with Soft Tissues, Acta Biomater., 2015, 13, 1-15.

9 L. C. Gerhardt, K. L. Widdows, M. M. Erol, C. W. Burch, J. A. Sanz-Herrera, I. Ochoa, R. Stämpfli, I. S. Roqan, S. Gabe, T. Ansari and A. R. Boccaccini, The ProAngiogenic Properties of Multi-Functional Bioactive Glass Composite Scaffolds, Biomaterials, 2011, 32, 4096-4108.

10 A. P. Gupta and V. Kumar, New Emerging Trends in Synthetic Biodegradable Polymers-Polylactide: A Critique, Eur. Polym. J., 2007, 43, 4053-4074.

11 J. Blaker, V. Maquet, R. Jérome, A. R. Boccaccini and S. N. Nazhat, Mechanical Properties of Highly Porous PDLLA/Bioglass Composite Foams as Scaffolds for Bone Tissue Engineering, Acta Biomater., 2005, 1, 643-652.

12 J. Blaker, A. Bismarck, A. R. Boccaccini, A. M. Young and S. N. Nazhat, Premature Degradation of $\operatorname{Poly}(\alpha-$ 
hydroxyesters) During Thermal Processing of Bioglass ${ }^{\circledR}-$ Containing Composites, Acta Biomater., 2010, 6, 756-762.

13 A. Larrañaga and J. R. Sarasua, Effect of Bioactive Glass Particles on the Thermal Degradation Behaviour of Medical Polyesters, Polym. Degrad. Stab., 2013, 98, 751-758.

14 T. Niemela, H. Niiranen, M. Kellomaki and P. Tormala, SelfReinforced Composites of Bioabsorbable Polymer and Bioactive Glass with Different Bioactive Glass Contents. Part 1: Initial Mechanical Properties and Bioactivity, Acta Biomater., 2005, 1, 235-242.

15 H. Niiranen, T. Pyhältö, P. Rokkanen, M. Kellomäki and P. Tormala, In Vitro and In Vivo Behavior of SelfReinforced Bioabsorbable Polymer and Self-Reinforced Bioabsorbable Polymer/Bioactive Glass Composites, J. Biomed. Mater. Res., Part A, 2004, 69, 699-708.

16 A. Larrañaga, S. Petisco and J. R. Sarasua, Improvement of Thermal Stability and Mechanical Properties of Medical Polyesters Composites by Plasma Surface Modification of the Bioactive Glass Particles, Polym. Degrad. Stab., 2013, 98, 1717-1723.

17 M. E. Lynge, R. van der Westen, A. Postma and B. Städler, Polydopamine-a Nature-Inspired Polymer Coating for Biomedical Science, Nanoscale, 2011, 3, 4916-4928.

18 H. Lee, S. M. Dellatore, W. M. Miller and P. B. Messersmith, Mussel-Inspired Surface Chemistry for Multifunctional Coatings, Science, 2007, 318, 426-431.

19 H. Shen, J. Guo, H. Wang, N. Zaho and J. Xu, Bioinspired Modification of h-BN for High Thermal Conductive Composite Films with Aligned Structure, ACS Appl. Mater. Interfaces, 2015, 7, 5701-5708.

20 H. Wang, C. Wu, X. Liu, J. Sun, G. Xia, W. Huang and R. Song, Enhanced Mechanical and Thermal Properties of Poly(L-lactide) Nanocomposites Assisted by PolydopamineCoated Multiwalled Carbon Nanotubes, Colloid Polym. Sci., 2014, 292, 2949-2957.

$21 \mathrm{H}$. Wu and M. R. Kessler, Multifunctional Cyanate Ester Nancomposites Reinforced by Hexagonal Boron Nitride after Noncovalent Biomimetic Functionalization, ACS Appl. Mater. Interfaces, 2015, 7, 5915-5926.

22 L. Yang, S. L. Phua, C. L. Toh, L. Zhang, H. Ling, M. Chang, D. Zhou, Y. Dong and X. Lu, Polydopamine-Coated Graphene as Multifunctional Nanofillers in Polyurethane, RSC Adv. , 2013, 3, 6377-6385.

23 L. Yang, W. A. Yee, S. L. Phua, J. Kong, H. Ding, J. W. Cheah and X. Lu, A High Throughput Method for Preparation of Highly Conductive Functionalized Graphene and Conductive Polymer Nanocomposites, RSC Adv., 2012, 2, 2208-2210.

24 L. Zhu, Y. Lu, Y. Wang, L. Zhang and W. Wang, Preparation and Characterization of Dopamine-Decorated Hydrophilic Carbon Black, Appl. Surf. Sci., 2012, 258, 5387-5393.

25 T. Kokubo and H. Takadama, How Useful is SBF in Predicting In Vivo Bone Bioactivity?, Biomaterials, 2006, 27, 2907-2915.

26 J. Blaker, J. E. Gough, V. Maquet, I. Notingher and A. R. Boccaccini, In Vitro Evaluation of Novel Bioactive
Composites Based on Bioglass-Filled Polylactide Foams for Bone Tissue Engineering Scaffolds, J. Biomed. Mater. Res., Part A, 2003, 67, 1401-1411.

27 M. R. Filgueiras, G. Latorre and L. L. Hench, Solution effects on the surface-reactions of a bioactive glass, J. Biomed. Mater. Res., 1993, 27, 445-453.

28 R. A. Zangmeister, T. A. Morris and M. J. Tarlov, Characterization of Polydopamine Thin Films Deposited at Short Times by Autoxidation of Dopamine, Langmuir, 2013, 29, 8619-8628.

29 G. Perego, G. D. Cella and C. Bastioli, Effect of Molecular Weight and Crystallinity on Poly(Lactic Acid) Mechanical Properties, J. Appl. Polym. Sci., 1996, 59, 37-43.

30 H. Lönnberg, K. Larsson, T. Lindström, A. Hult and E. Malmström, Synthesis of Polycaprolactone-Grafted Microfibrillated Cellulose for Use in Novel Bionanocomposites-Influence of the Graft Length on the Mechanical Properties, ACS Appl. Mater. Interfaces, 2011, 3, 1426-1433.

31 J. M. Ugartemendia, A. Larrañaga, H. Amestoy and J. R. Sarasua, Supramolecular Evolution Overa n Initial Period of Biodegradation of Lactide and Caprolactone Based Medical (Co)polyesters, Polym. Degrad. Stab., 2014, 198, 87-96.

32 J. R. Sarasua and J. Pouyet, Dynamic Mechanical Behavior and Interphase Adhesion of Thermoplastic (PEEK, PES) Short Fiber Composites, J. Thermoplast. Compos. Mater., 1998, 11, 2-21.

33 N. Ljungberg and B. Wesslén, Tributyl Citrate Oligomers as Plasticizers for Poly(lactic acid): Thermo-Mechanical Films Properties and Aging, Polymer, 2003, 44, 7679-7688.

34 O. Martin and L. Avérous, Poly(lactic acid): Plasticization and Properties of Biodegradable Multiphase Systems, Polymer, 2001, 42, 6209-6219.

35 J. Ryu, S. H. Ku, H. Lee and C. B. Park, Mussel-Inspired Polydopamine Coating as a Universal Route to Hydroxyapatite Crystallization, Adv. Funct. Mater., 2010, 20, 2132-2139.

36 C. Wu, W. Fan, J. Chang and Y. Xaio, Mussel-Inspired Porous $\mathrm{SiO}_{2}$ Scaffolds with Improved Mineralization and Cytocompatibility for Drug Delivery and Bone Tissue Engineering, J. Mater. Chem., 2011, 21, 18300-18307.

37 J. Xie, S. Zhong, B. Ma, F. D. Shuler and C. T. Lim, Controlled Biomineralization of Electrospun Poly( $\varepsilon$-caprolactone) Fibers to Enhance their Mechanical Properties, Acta Biomater., 2013, 9, 5698-5707.

38 M. Xu, Y. Zhang, D. Zhai, J. Chang and C. Wu, MusselInspired Bioactive Ceramics with Improved Bioactivity, Cell Proliferation, Differentiation and Bone-Related Gene Expression of MC3T3 Cells, Biomaterials Sciences, 2013, 1, 933-941.

39 P. Yan, J. Wang, L. Wang, B. Liu, Z. Lei and S. Yang, The In Vitro Biomineralization and Cytocompatibility of Polydopamine Coated Carbon Nanotubes, Appl. Surf. Sci., 2011, 257, 4849-4855. 